\title{
Recurrent Abortion in a Patient with Ebstein Anomaly
}

\author{
Abdolmohammad Ranjbar ${ }^{1}$, Razieh Parizad ${ }^{1}$, Mehrnoush Toufan Tabrizi $^{1^{*}}$
}

\begin{abstract}
Most maternal cardiac disease in Western societies is now congenital in origin. This relates to the significant improvements in congenital cardiac surgery during the last years. Some patients will present for the first time in pregnancy with symptoms and learn that they have congenital heart disease. So all patients should have a detailed evaluation and appropriate counseling before pregnancy. Ebstein anomaly is a rare and complex congenital heart disorder occurring in 1 per 200000 live births and, first described by a German physician Wilhelm Ebstein in 1866 in a report titled, "Concerning a very rare case of insufficiency of the tricuspid valve caused by a congenital malformation. This anomaly accounts for $0.5 \%-0.7 \%$ of cases of congenital heart disease. The average life duration of patients with Ebstein's anomaly is $25-30$ years. The malformation consists of apical displacement of the tricuspid valve with resultant regurgitation and enlargement of the right heart chambers, resulting in arrhythmias and heart failure. The common cardiac anomalies associated with the condition are atrial septal defect (ASD) in $90 \%$ of patients, anatomic or functional tricuspid atresia in $30 \%$, Wolff-Parkinson-White (WPW) syndrome in 15\% and less commonly ventricular septal defect (VSD), pulmonic stenosis or atresia and mitral valve prolapse. Survival into adulthood is common and patients present with cyanosis, dyspnea and palpitations. Keywords: Box Shaped Heart, Ebstein Anomaly, Pregnancy, Recurrent Abortion
\end{abstract}

\section{Introduction}

Most maternal cardiac disease in Western societies is now congenital in origin. This relates to the significant improvements in congenital cardiac surgery during the last years. Some patients will present for the first time in pregnancy with symptoms and learn that they have congenital heart disease (1). So all patients should have a detailed evaluation and appropriate counseling before pregnancy (2).

Ebstein anomaly is a rare and complex congenital heart disorder occurring in 1 per 200,000 live births and, first described by a German physician Wilhelm Ebstein in 1866 in a report titled, "Concerning a very rare case of insufficiency of the tricuspid valve caused by a congenital malformation". This anomaly accounts for $0.5 \%-0.7 \%$ of cases of congenital heart disease (3-7). The average life duration of patients with Ebstein's anomaly is 25-30 years (8-9). The malformation consists of apical displacement of the tricuspid valve with resultant regurgitation and enlargement of the right heart chambers, resulting in arrhythmias and heart failure $(10,11)$. The common cardiac anomalies associated with the condition are atrial septal defect (ASD) in $90 \%$ of patients, anatomic or functional tricuspid atresia in 30\%, Wolff-ParkinsonWhite (WPW) syndrome in 15\% and less commonly ventricular septal defect (VSD), pulmonic stenosis or atresia and mitral valve prolapse. Survival into adulthood is common and patients present with cyanosis, dyspnea and palpitations $(6,11,12)$.

\section{Case Report}

A 23 years old woman, referred to our Hospital
(Madani Heart Center) from a General Hospital for Echocardiography and better evaluation of cardiovascular system. The patient had an unsuccessful pregnancy with fetal loss about two weeks ago at gestational age of 29 week when dyspnea, respiratory distress and cyanosis was exacerbated. In past medical history recurrent abortions (five times) were significant. In medical workup of the patient (gynecology, obstetric and internal medicine) no significant problem other than dyspnea on exertion and palpitation with exacerbation during pregnancy was reported. On arrival, the patient's vital signs were: $\mathrm{PR}=80 \mathrm{bpm}, \mathrm{BP}=125 / 80 \mathrm{~mm} \mathrm{Hg}, \mathrm{RR}=20 \mathrm{~min}, \mathrm{~T}=37.5$ $\mathrm{C}$ and the oxygen saturation of $88 \%$ with oxygen delivered by nasal cannula.

Lab data: $\mathrm{Hct}=45.2, \mathrm{Hb}=16.3, \mathrm{Plt}=234000, \mathrm{Cr}=0.8$

\section{Follow up}

The patient referred for operation. TV repair and ASD closure was done. 14 weeks after discharge from the hospital, the patient was followed and there was no new problems in her clinical situation. The patient advice to have regular follow-up during the next pregnancy and peripartum period, and must be closely monitored by obstetrician and cardiologist.

\section{Post operation Echo}

Status, post TV repair and ADS closure (Ebstein anomaly): Mild LV systolic dysfunction. EF=40-45\% Near Severe TR, Nl PAP, TRG=19, Apical displacement of posterior and septal leaflets of TV, No detectable residual defect in ASD with contrast study. MVP, Mild MR, Right atrial enlargement, atrialized RV, functional $\mathrm{RV}=40 \%$ (total 
RV), No Pericardial effusion, No visible clot (Figures 1-3).

\section{Discussion}

Pregnancy is usually well tolerated in patients with ebstein anomaly, but there is an increased risk of fetal loss, prematurity and low birth weight (5). During pregnancy secondary to low systemic vascular resistance, hypercoagulable state, increased blood volume, increased cardiac output, increased sympathetic drive and raised concentration of catecholamine particularly during hypoxia and stress, the cardiac symptoms may exacerbate to congestive heart failure, right heart failure, increased right-to-left shunt, and cyanosis. If preeclampsia develops in a patient with Ebstein's anomaly, which is associated with increased systemic vascular resistance, it can predispose to congestive cardiac failure (2-6). Prematurity and risk of abortion is usually increased in these patients,

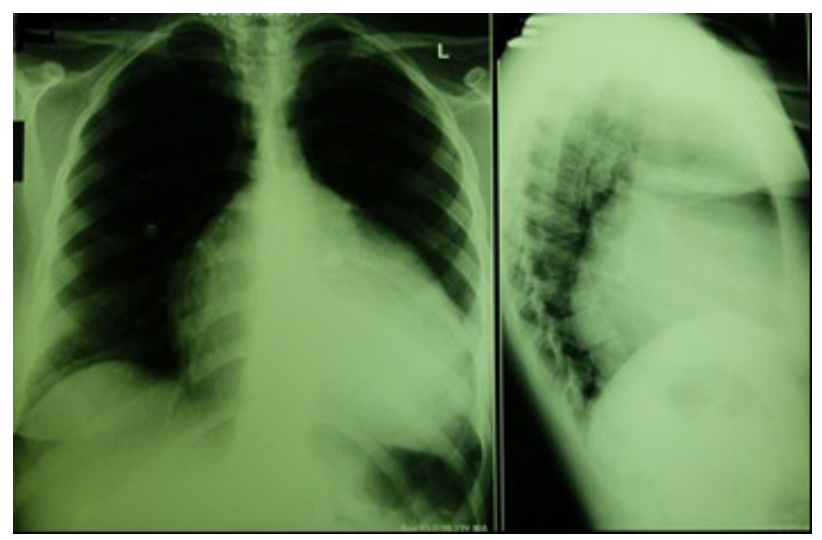

Figure 1. CXR: The right atrium is enlarged. The left atrium is normal in size, but the left cardiac contour has a shelved appearance because of the dilated right ventricular outflow tract. The aorta is small, and the pulmonary trunk is absent. This combination of features produces a cardiac silhouette that has been described as box shaped heart.

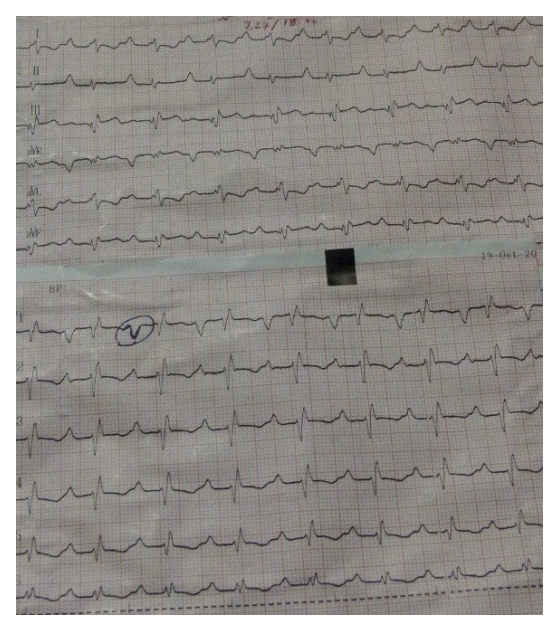

Figure 2. ECG: Extremely tall $P$ waves indicative of right atrium enlargement. The QRS complex in lead V1, appearing as in the case of an atypical RBBB. There is also generally wide and low QRS voltage. PR interval is prolonged (First-degree AV block).

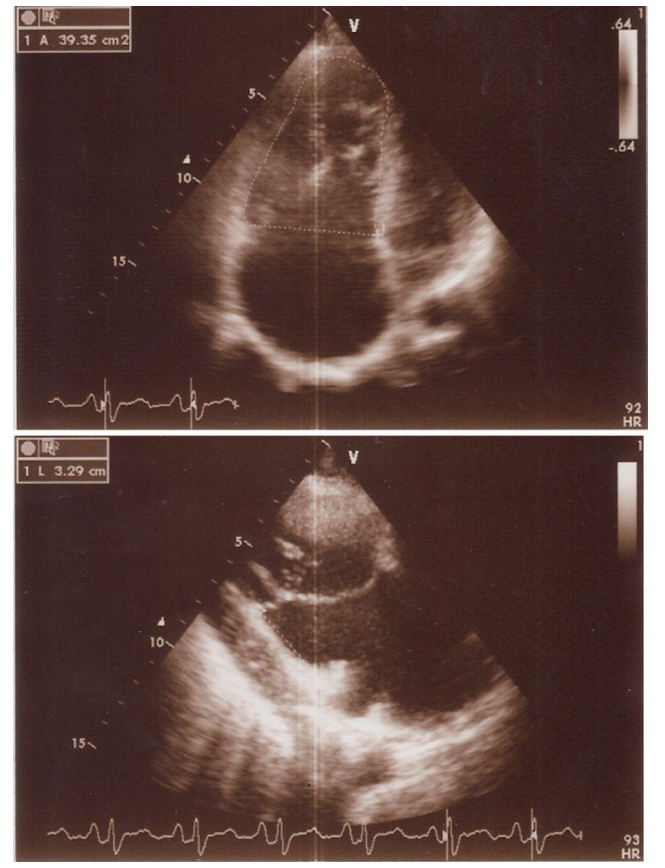

Figure 3. Echocardiography (TTE and TEE) showed: Typical Ebstein anomaly, small LV cavity with under filled and mildly reduced systolic function, Right ventricle is partitioned to atrialized RV \& functional RV, FRV/TRV $=40 \%$, Left atrium size is normal, Right atrium size is enlarged, Tricuspid valve has displacement of posterior leaflet to apex $(6.37 \mathrm{~cm})$ and displacement of septal leaflet to apex $(5 \mathrm{~cm})$ with severe TR and normal PAP. Inter atrial septum has secundum type ASD at fossa ovalis (size=1.4 cm) with left to right shunt. Pericardium is normal.

depending on maternal cardiac dysfunction (7).

Supraventricular arrhythmias, WPW syndrome or atrial fibrillation, adversely affect maternal mortality in Ebstein's anomaly and require aggressive and prompt management as they can result in rapid hemodynamic compromise in an already diseased heart. Maternal mortality is usually $<1 \%$ in New York Heart Association (NYHA) class 1, but increases to $5-15 \%$ if associated with severe disease or atrial fibrillation (3).

The management of these patients during labor requires avoiding all factors which can lead to congestive cardiac failure, cyanosis and arrhythmias. This includes prevention of changes in both preload and afterload to avoid increased right-to-left shunt, which can be achieved by adequate fluid replacement prevention as well as timely management of postpartum hemorrhage to avoid hypotension. However, fluid overload during labor should be avoided to prevent cardiac failure $(1,2,6)$. To maintain normal sinus rhythm during labor, adequate pain relief in the form of epidural analgesia is helpful, and can be upgraded to anesthesia if cesarean section is indicated (8). In a retrospective analysis (5) of 111 pregnancies in 44 women with Ebstein's anomaly, 89\% delivered vaginally, $76 \%$ pregnancies ended in live births and there was no maternal mortality. In another study of 42 pregnancies in 12 women with Ebstein's anomaly, there were 36 live births; three underwent cesarean section, while the remaining women had vaginal delivery, and four had 
forceps application. Congenital heart disease and Ebstein's anomaly is seen in $6 \%$ and $0.6 \%$ of infants, respectively, born to mothers with Ebstein's anomaly (5). Maternal lithium use for the treatment of affective disorders during the first trimester of pregnancy has been reported to cause Ebstein's anomaly in offspring (8). Ebstein's anomaly does not have any effect on fertility, even in women with cyanosis (5). Operative treatment to improve quality in the form of tricuspid valve reconstruction, valve replacement, and modified Fontan operation was performed in 189 patients in the 11 months to 64 years age group, along with successful ablation of accessory conduction pathways $(9,10)$. Women who have undergone cardiac repair are also reported to tolerate pregnancy well (5).

\section{Recommendations}

Recommendations for Surgical Interventions Class I Surgeons with training and expertise in CHD should perform tricuspid valve repair or replacement with concomitant closure of an ASD, when present, for patients with Ebstein's anomaly with the following indications:

a) Symptoms or deteriorating exercise capacity. (Level of Evidence: B)

b) Cyanosis (oxygen saturation less than 90\%). (Level of Evidence: B)

c) Paradoxical embolism. (Level of Evidence: B)

d) Progressive cardiomegaly on chest X-ray. (Level of Evidence: B)

e) Progressive RV dilation or reduction of RV systolic function. (Level of Evidence: B)

\section{Recommendation for Reproduction Class I}

Women with Ebstein's anomaly should undertake prepregnancy counseling with a physician with expertise in Adult CHD (Level of Evidence: C).

Most women with Ebstein's anomaly can have a successful pregnancy with proper care, but there is an increased risk of low birth weight and fetal loss if significant cyanosis is present. The risk of CHD in the offspring (in the absence of a family history) is approximately $6 \%(11)$.

\section{Conclusion}

Patients with Ebstein's anomaly can tolerate pregnancy, so termination of pregnancy or advice against becoming pregnant is not indicated. These pregnant women needs to regular follow-up during the pregnancy and peripartum period, and must be closely monitored for any complications; development of heart failure, arrhythmias and cyanotic spells for achievement to optimum maternal and neonatal outcomes.

\section{Ethical issues}

Written informed consent was obtained from the patient for publication of this Case report and any accompanying images and The local ethics committee approved the study.

\section{Conflict of interests}

There are no financial or non-financial competing interests.

\section{Acknowledgments}

We would like to thank all of our colleagues who helped us in this study.

\section{References}

1. Groves ER, Groves BJ. Epidural analgesia for labour in a patient with Ebstein's anomaly. Can J Anaesth 1995; 42: 77-9.

2. Linter SP, Clarke K. Caesarean section under extradural analgesia in a patient with Ebstein's anomaly. Br J Anaesth 1984;56: 203-5.

3. Misa VS, Pan PH. Evidence-based case report for analgesic and anesthetic management of a parturient with Ebstein's anomaly and Wolff-Parkinson-White syndrome. Int J Obstet Anaesth 2007; 16: 77-81.

4. Gultekin F, Baskin E, Gokalp A, Dogan K. A pregnant woman with Ebstein's anomaly. A case report. Mater Med Pol 1994; 26: 149-51.

5. Connolly HM, Warnes CA. Ebstein's anomaly: Outcome of pregnancy. J Am Coll Cardiol 1994; 23:1194-8.

6. Santosh JM, Esteves M, Silva MJ, Silva E, Barbosa MA, Da Palma-Carlos AG. Ebstein's anomaly of the tricuspid valve. Clinical tolerance up to 38 years of age and pregnancy. Acta Med Port 1994;7: 627-30.

7. Correa-Villasenor A, Ferencz C, Neill CA, Wilson PD, Boughman JA. Ebstein's malformation of the tricuspid valve: Genetic and environmental factors. The Baltimore Washington Infant. Teratology 1994;50:137-47.

8. Pinelli JM, Symington AJ, Cunningham KA, Paes BA. Case report and review of the perinatal implications of maternal lithium use. Am J Obstet Gynecol 2002;187: 245-9.

9. Danielson GK, Driscoll DJ, Mair DD, Warnes CA, Oliver WC Jr. Operative treatment of Ebstein's anomaly. J Thorac Cardiovasc Surg 1992; 104: 1102-95.

10. Behl P, Blesovsky A. Ebstein's anomaly: Sixteen years experience with valve replacement without placation of the right ventricle. Thorax 1984; 39: 8-13.

11. Warnes CA, Williams RG, Bashore TM, Child JS, Connolly HM, Dearani JA, et al. ACC/AHA 2008 Guidelines for the Management of Adults With Congenital Heart Disease. Executive Summary: A Report of the American College of Cardiology/American Heart Association Task Force on Practice Guidelines (Writing Committee to Develop Guidelines for the Management of Adults With Congenital Heart Disease). Circulation 2008;118:2395-51.

Copyright $\odot 2014$ The Author(s); This is an open-access article distributed under the terms of the Creative Commons Attribution License (http://creativecommons.org/licenses/by/4.0), which permits unrestricted use, distribution, and reproduction in any medium, provided the original work is properly cited. 